ISSN: 1410-8917

Jurnal Kimia

-Sains \&

Aplikasi

e-ISSN: 2597-9914
Jurnal Kimia Sains dan Aplikasi Journal of Scientific and Applied Chemistry

Journal homepage: http://ejournal.undip.ac.id/index.php/ksa

\title{
Heat Properties of Polylactic Acid Biocomposites after Addition of Plasticizers and Oil Palm Frond Microfiber
}

\author{
Wida Banar Kusumaningrum ${ }^{\mathrm{a}, *}$, Firda Aulya Syamani ${ }^{a}$, Lisman Suryanegara ${ }^{a}$ \\ ${ }^{\text {a }}$ Biomaterials Research Center - Indonesian Institute of Sciences, Cibinong, Bogor, Indonesia \\ * Corresponding author: wida.banar@biomaterial.lipi.go.id \\ https://doi.org/10.14710/jksa.23.8.295-304
}

\section{Article Info}

Article history:

Received: $29^{\text {th }}$ May 2020 Revised: $14^{\text {th }}$ July 2020 Accepted: $28^{\text {th }}$ July 2020 Online: $31^{\text {st }}$ August 2020

Keywords: non-isothermal crystallization kinetics; polyethylene glycol; polylactic acid; oil palm frond microfiber; triacetin

\begin{abstract}
Polylactic acid (PLA) is a biopolymer that can replace thermoplastic polymers such as polypropylene (PP) in various applications due to strength, young modulus, biocompatibility, biodegradability, good clarity, oil resistance, and oxygen barrier ability. However, PLA has some drawbacks, including brittle, high glass transition temperature $\left(\mathrm{T}_{\mathrm{g}}\right)$, and low degradation and crystallization rates. Therefore, modification is needed with the addition of nucleating agents and plasticizers to overcome these limitations of PLA. This research aims to study the effect of plasticizers and microfibril cellulose of oil palm frond (OPF) on thermal stability and to review the crystallization kinetics of PLA biocomposites. Polyethylene glycol and triacetin were used as plasticizers. Thermal analysis was performed using Thermal Gravimetry analysis (TGA) and Differential Scanning Calorimetry (DSC). The crystallization kinetics study was analyzed using a modified Avrami model under non-isothermal conditions. PLAP4000 has better thermal stability than PLAP200 and PLAG with $\mathrm{T}_{\text {onset }}$ and $\mathrm{T}_{\max }$ values reaching $349.17^{\circ} \mathrm{C}$ and $374.68^{\circ} \mathrm{C}$, respectively, which are close to pure PLA. All types of plasticizers influenced decreasing the $\mathrm{T}_{\mathrm{g}}$ value in the range of $27-42 \%$, whereas $\mathrm{OPF}$ microfiber addition contributes to a $\mathrm{T}_{\mathrm{g}}$ reduction of $37-55 \%$. Crystallization kinetic study was informed for heterogeneous and simultaneous nucleation mechanisms with an $\mathrm{n}$ value range of about 2-3 for PLAP 4000 and PLAOP4000. The crystallization rate was multiplied 4-9-fold for PLAOP200 and 2-3-fold for PLAOP4000.
\end{abstract}

\section{Introduction}

The substitution of fossil-based polymers such as polypropylene and polyethylene with polymers that are easily biodegradable in the environment such as polylactic acid and polyhydroxy butyrate is becoming very important, amid issues of sustainability and a sustainable green industry movement. These fossilbased thermoplastic polymers are widely used in various applications, so their use and management must be controlled because they cannot be biodegradable in the environment. Polylactic acid (PLA) is a biopolymer that has the potential to replace thermoplastic polymers such as polypropylene (PP) for several applications, because it has good strength and firmness, with 2 times the tensile strength and 2.5 times the young modulus, higher than PP [1]. It is also biocompatible, biodegradable, good transparency, good oil resistance, and oxygen barrier ability $[2,3,4,5]$. In connection with these properties, PLA can be applied to packaging and health materials, as well as automotive components [2, 3, 4]. Besides, the PLA manufacturing process has advantages in the heating process's effectiveness compared to other biopolymers and is more energy-efficient than fossilsourced polymers [2]. PLA, which is synthesized by fermentation of molasses from biological sources such as sugarcane and corn is believed to be more economical and affordable [6]. However, through the fermentation process, the PLA obtained produced different molecular weights and crystal structures. PLA is polymorphic, which has three dimensions of the main crystal structure, which are $\alpha$ (orthorhombic), $\beta$ (parallel orthorhombic), and $\gamma$ (antiparallel helices arrangement) $[7,8,9]$. 
The polymorph nature of the PLA requires control during the heating and cooling process. It affects the crystal structure formed, which has an impact on changing its mechanical and physical properties. PLA has several limitations, including brittleness, high glass transition temperature $\left(\mathrm{T}_{\mathrm{g}}\right)$, which is close to room temperature ranging from $56-65^{\circ} \mathrm{C}$, low rates of degradation and crystallization $[2,4,8,10]$. Efforts are being made to improve the properties of PLA through intramolecular and intermolecular modifications. Effective modifications include the addition of nucleating agents, plasticizers, and a combination of both $[2,4,6,11]$.

Modification with plasticizers aims to increase the elasticity of PLA. The plasticizer mechanism in PLA is to insert plasticizers between the PLA molecular chains, thereby decreasing the rotational energy of the C-C bonds, which results in a decrease in $\mathrm{T}_{\mathrm{g}}$ [12]. Some plasticizers can be used in PLA, both low and high molecular weights, including glycerol, triacetin, polyethylene glycol, lactic acid oligomers, and plasticized starch $[6,13]$. The addition of plasticizers with low molecular weight, such as citrate esters, glycerol, and glucose monoesters, can increase (ductility) and impact resistance [14]. The ease of molecular chain mobility due to plasticization, significantly affects PLA's thermal characteristics, especially $\mathrm{T}_{\mathrm{g}}$ and crystallization temperature $\left(\mathrm{T}_{\mathrm{c}}\right)$. The addition of plasticizers, both low and high molecular weight, can reduce the $\mathrm{T}_{\mathrm{g}}$ of PLA $[6,14,15,16,17,18]$. Some studies state an increase in $\mathrm{T}_{c}$, which shows a more regular crystal structure [19, 20]. Zubir et al. [11], Choi et al. [14] and Septevani and Bhakri [12] emphasized that plasticizers with low molecular weight have the potential to migrate, thereby reducing the elasticity of PLA over a while. Meanwhile, the plastic composition that is too high will reduce the mechanical properties of PLA. Another modification is the addition of a nucleating agent to accelerate the formation of nuclei, one of which is by strengthening natural fibers. Apart from being a nucleating agent, oil palm frond (OPF) microfiber can also be used as a reinforcing agent, thereby increasing the mechanical properties of PLA composites. Several studies stated that there was a decrease in $\mathrm{T}_{\mathrm{g}}$ of PLA with the addition of microfiber by about 3\% [21], $5 \%$ [22] to $15 \%$ [23] compared to pure PLA. The addition of $10 \%$ MFC (microfibril cellulose) was able to increase the crystallinity of PLA up to $32 \%$ and decrease the cold crystallization temperature $\left(\mathrm{T}_{\mathrm{cc}}\right)[22,24]$. Apart from increased crystallinity, the addition of MCC (microcrystalline cellulose) from oil palm empty fruit bunches also improved the heat stability of PLA [25].

In thermoplastic polymers such as PLA, thermal analysis is indispensable because it affects the choice of production processes, handling, and storage. Modifications with the addition of nucleating agents and plasticizers will affect the thermal characteristics of PLA composites, primarily if the heating and cooling strongly influence the microstructure. In this research, a study of the effect of 3 types of plasticizers is glycerol triacetate (GTA) and polyethylene glycol (PEG) with low molecular weight, and PEG with high molecular weight. Also, as a nucleating agent, microfibers from oil palm frond (OPF) pulp were added. The mixing process generally uses an injection process, while in this study, the mixing was carried out by casting with a solvent casting. Therefore, it is necessary to do a thermal analysis because of additives and differences in processes. This study aimed to study the effect of plasticizer and OPF microfiber on thermal characteristics and a review of crystallization kinetics on PLA composites.

\section{Methodology}

This research consists of raw materials preparation, synthesis of PLA biocomposites, thermal analysis of PLA biocomposites, and a review of crystallization kinetics of PLA biocomposites.

\subsection{Material}

Oil palm frond fiber was obtained from the PTPN VIII Sukamaju plantation, West Java. Processing fiber into pulp through a sulfate (kraft) process was carried out at the Center for Pulp and Paper (BBKK) Bandung. PLA (polylactic acid) D3001 semicrystalline was obtained from Natureworks, USA, with a specific gravity of 1.24 $\mathrm{g} / \mathrm{cm}^{3}$ and a melt flow rate of $22 \mathrm{~g} / 10 \mathrm{~min}$. The plasticizers used were GTA (glycerol triacetate) and PEG (polyethylene glycol) with low and high molecular weight. GTA pro analysis was obtained from Wako Pure Chemical Industries Ltd with a density of 1.157-1.165 $\mathrm{g} / \mathrm{cm}^{3}$ and a molecular weight of $218.2 \mathrm{~g} / \mathrm{mol}$. The PEG used had a low molecular weight of 190-200 g/mol (PEG 200) with a density of $1.157-1.165 \mathrm{~g} / \mathrm{cm}^{3}$, while the high molecular weight was 3500-4500 g/mol (PEG 4000) with a density of $1.2 \mathrm{~g} / \mathrm{cm}^{3}$. The PEG 200 and PEG 4000 pro analyzes were obtained from Merck, Indonesia. The materials used for the pulp bleaching process were sodium chloride $25 \%$ solution in water, and glacial acetic acid $100 \%$ pro analysis obtained from Merck Indonesia. Meanwhile, for the PLA composite manufacturing process, 99\% dichloromethane (DCM), 96\% ethanol, and $90 \%$ acetone were used technically purchased from Frisconina.

\subsection{Bleaching of oil palm frond pulp}

OPF pulp with $10 \mathrm{~g}$ oven-dry weight was added 600 $\mathrm{mL}$ of distilled water. Sodium chloride and glacial acetic acid as delignification agents were added to the mixture, $16 \mathrm{~mL}$ and $0.8 \mathrm{~mL}$, respectively. The bleaching process was carried out in a water bath at $80^{\circ} \mathrm{C}$ for 1 hour with periodic stirring every 15 minutes. The lighter colored pulp was then filtered and washed with distilled water until the $\mathrm{pH}$ is neutral, odorless, and clean. The bleached pulp yield was then referred to as OPF. The bleached OPF pulp's chemical composition was $4.53 \%$ lignin, $9.22 \%$ hemicellulose, and $86.25 \%$ cellulose.

\subsection{Biocomposite Film Preparation}

The PLA biocomposite manufacturing process went through several stages: raw material preparation, mixing, and molding. The solvent exchange process was carried out in 2 stages, first, using $96 \%$ ethanol stirred with pulp for 1 hour, followed by acetone stirring for 1 
hour. PLA was dissolved with DCM and added 10\% (w/w) of plasticizer then stirred for 60 minutes. As much as $10 \%(\mathrm{w} / \mathrm{w})$ of OPF pulp was added to the PLA solution and plasticizer, then stirred again for 15 minutes. After the mixing process, the solution was spread out on a teflon mat and dried at room temperature for 24 hours. PLA films were molded using a hot press at $170^{\circ} \mathrm{C}$ for 30 seconds at a pressure of $1 \mathrm{MPa}$. Film sheets were cut with $5 \times 5 \mathrm{~mm}$ dimensions for testing thermal properties using DSC and TGA. The test samples were coded, as shown in Table 1.

Table 1. Sample code for PLA biocomposite test

\begin{tabular}{cc}
\hline Sample codes & Explanation \\
\hline PLA & Pure PLA \\
PLAG & PLA + GTA 10\% \\
PLAP200 & PLA + PEG200 10\% \\
PLAP4000 & PLA + PEG4000 10\% \\
PLAO & PLA + OPF 10\% \\
PLAOG & PLA + GTA 10\% + OPF 10\% \\
PLAOP200 & PLA + PEG200 10\% + OPF 10\% \\
PLAOP4000 & PLA + PEG4000 10\% + OPF 10\% \\
\hline
\end{tabular}

\subsection{Morphological analysis of OPF pulp fibers}

OPF pulp fiber morphological analysis was carried out using Field Emission Scanning Electron Microscope (FE-SEM) - Quattro S Thermo Fisher Scientific. The OPF pulp fibers were placed in a step without coating, then analyzes were carried out at magnifications of 100,500 , and 1000 times by scanning electrons at $2 \mathrm{kV}$.

\subsection{Thermal Properties Analysis}

\subsubsection{Thermal Gravimetry Analysis (TGA)}

TGA analysis using the TGA 4000 Perkin Elmer. A test sample of $10 \mathrm{mg}$ was placed in a ceramic crucible in a combustion chamber flowing with nitrogen gas. The test sample is heated from $25^{\circ} \mathrm{C}$ to $500^{\circ} \mathrm{C}$ with a heating rate of $10^{\circ} \mathrm{C} / \mathrm{min}$.

\subsubsection{Differential Scanning Calorimetry (DSC)}

The characterization of the thermal properties of the PLA biocomposite was carried out using the DSC 4000 Pyris 1 Perkin Elmer, which was equipped with a cooler. The results of the DSC analysis are the thermal parameters of polymer, including $\mathrm{T}_{\mathrm{g}}$ (glass transition temperature), $\mathrm{T}_{\mathrm{m}}$ (melting temperature), $\mathrm{T}_{\mathrm{cc}}$ (cold crystallization temperature), $\mathrm{T}_{\mathrm{c}} \quad$ (crystallization temperature), melting enthalpy and crystallization enthalpy.

The DSC analysis stages included heating from $25^{\circ} \mathrm{C}$ to $250^{\circ} \mathrm{C}$ with a heating rate of $10^{\circ} \mathrm{C} / \mathrm{min}$. Then the samples were held at $250^{\circ} \mathrm{C}$ for 1 minute. Then cooled from $250^{\circ} \mathrm{C}$ to $-25^{\circ} \mathrm{C}$ with a cooling rate of $10^{\circ} \mathrm{C} / \mathrm{min}$. Samples were held at $-25^{\circ} \mathrm{C}$ for 1 minute. Then the samples were heated again from $-25^{\circ} \mathrm{C}$ to $250^{\circ} \mathrm{C}$ with a heating rate of $10^{\circ} \mathrm{C} / \mathrm{min}$. The results obtained are used to determine the degree of crystallization of the biocomposite using equation 1 .

$$
X c=\frac{\Delta H_{m}}{w \Delta H_{m}^{\circ}} \times 100 \%
$$

where $\mathrm{w}$ is the weight fraction of PLA in the composite, $\Delta \mathrm{H}_{\mathrm{m}}$ is the melting enthalpy of the biocomposite obtained at the second heating stage, while $\Delta \mathrm{H}_{\mathrm{m}}{ }^{\circ}$ is the melting enthalpy for PLA which has a degree of crystallinity of $100 \%$ with a value of $93 \mathrm{~W} / \mathrm{g}$ [26].

\subsection{Overview of Non-Isothermal Crystallization Kinetics}

The crystallization kinetics of the PLA system with the addition of plasticizer and OPF was carried out in non-isothermal conditions. This condition was chosen because, in real conditions, the biocomposite manufacturing process is carried out through a continuous process, including injection molding, blow molding, and extrusion. The crystallization kinetics analysis stage was heating from a temperature of $25^{\circ} \mathrm{C}$ to $200^{\circ} \mathrm{C}$ with a heating rate of $40^{\circ} \mathrm{C} / \mathrm{min}$. Then the samples were held at $200^{\circ} \mathrm{C}$ for 5 minutes, followed by cooling from $200^{\circ} \mathrm{C}$ to $0^{\circ} \mathrm{C}$ with set cooling rates of 5,10 , and $15^{\circ} \mathrm{C} / \mathrm{min}$. Kinetics analysis was carried out at the cooling (exothermic) process stage. The crystallization kinetics analysis approach used the Avrami model [27, 28]. Based on the assumption that total crystallization is linear with the energy released during the crystallization process, the relative crystallization degree $(\mathrm{X}(\mathrm{t}))$ can be described by equation 2 .

$$
X(t)=\frac{\int_{0}^{t}(\Delta H c / d t) d t}{\int_{0}^{\infty}(\Delta H c / d t) d t}
$$

$\mathrm{X}(\mathrm{t})$ is the volume fraction of the polymer that crystallizes at time $t, \Delta H_{c}$ is the crystallization enthalpy during the time interval $\mathrm{dt}$ (heat flow), $\mathrm{t}$ is the measured time during the crystallization process, $\infty$ is the time when crystallization ends. The crystallization kinetics parameters use the relative crystallization degree relationship with a constant from the Avrami model and are described by equation 3 .

$$
X(t)=1-\exp \left(-K t^{n}\right)
$$

$\mathrm{K}$ denotes the Avrami velocity constant, which includes the process of nucleation and crystal growth while $\mathrm{n}$ is the Avrami exponent, which shows the crystal geometry information. This constant can be obtained by the stratified logarithmic equation in equation 4 .

$$
\log [-\ln (1-X(t))]=n \log t+\log K
$$

The modification of Avrami model for nonisothermal process is at $\mathrm{t}$ which has a relationship with temperature and cooling rate as described in equation 5 [29], where $T$ is the temperature at the time of crystallization $t, T_{o}$ is the temperature at the beginning of crystallization, while $\emptyset$ is the velocity cooling down. Calculation of Avrami constants $\mathrm{K}$ and $\mathrm{n}$ by connecting the $\log$ graph $[-\ln (1-\mathrm{X}(\mathrm{t}))]$ with $\log \mathrm{t}$ so that the results $\mathrm{K}$ as the intercept and $\mathrm{n}$ as the slope.

$$
t=\frac{T-T o}{\emptyset}
$$




\section{Results and Discussion}

\subsection{Morphology of OPF pulp fiber}

The bleached OPF pulp has long fiber morphology with a high aspect ratio, as shown in Figure 1 (a). Figures 1 (b) and 1 (c) show that the fiber diameter ranges from 10-30 $\mathrm{\mu m}$. According to Zimmermann et al. [30], fibers with a diameter of less than $50 \mu \mathrm{m}$ with a millimeterscale length are called microfibrils.

a.

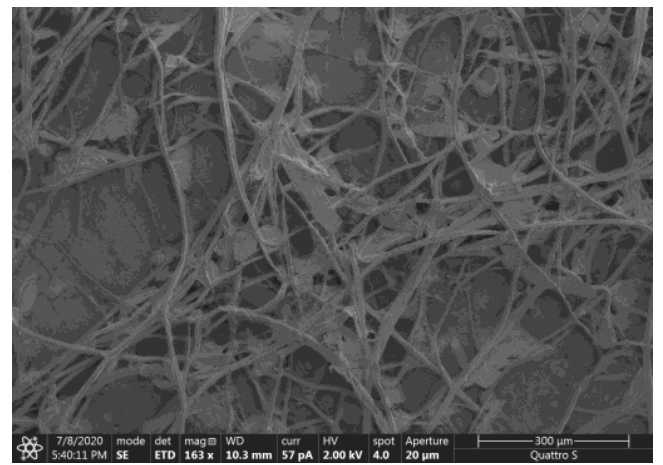

b.

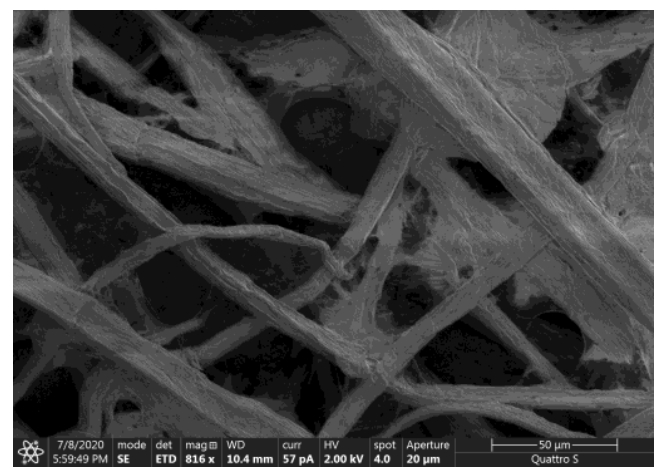

c.

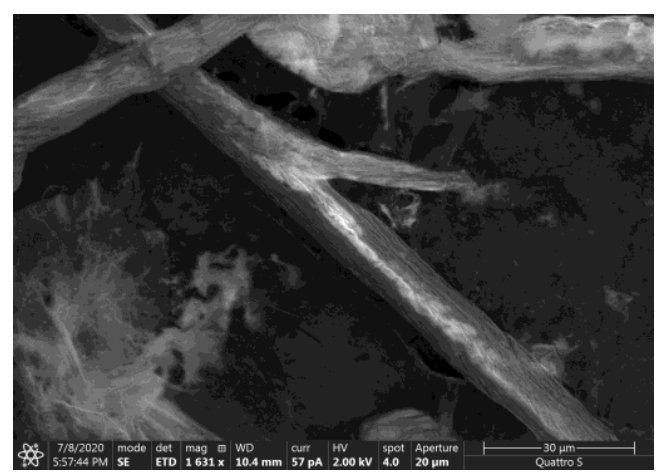

Figure 1. OPF pulp fiber morphology at magnifications of 100 times (a), 500 times (b), and 1000 times (c)

\subsection{Characterization of thermal stability properties of PLA biocomposite through TGA analysis}

The heat stability characteristic of PLA biocomposite is expressed by weight loss in temperature units obtained from TGA and DTG analysis. Figure 2(a) and Figure 2(b) show that the type of plasticizer affects the thermal stability of PLA biocomposites. The PEG-based plasticizer produces one decomposition peak, just like the pure PLA depicted in Figure 2 (b). However, there is a decrease in the initial decomposition temperature (Tonset) of PLAP200 and PLAP4000 compared to pure PLA, which are $11.5 \%$ and $2 \%$, respectively. The lower molecular weight PEG produces PLA with lower thermal resistance, compared to the higher molecular weight
PEG. This is because PEGs with higher molecular weight can be said more stable binds to the PLA polymer chain arrangement. Plasticizers with high molecular weight have longer polymer chains, so they are not easily decomposed [12]. Apart from that, it can also act as a protective layer to inhibit the permeability of volatile substances [31]. Quiles-Carrillo et al. [32] explained that the decrease in $\mathrm{T}_{\text {onset }}$ could be caused by the evaporation of the plasticizer and the low molecular weight. On the other hand, the GTA plasticizer has two Tonsets, as shown in Figure 2 (a) and two decomposition peaks shown in Figure 2 (b). The PLAG Tonset is at $135.96^{\circ} \mathrm{C}$ and $353.33^{\circ} \mathrm{C}$, while the peaks of decomposition are at $157.82^{\circ} \mathrm{C}$ and $376.69^{\circ} \mathrm{C}$. These results may occur because GTA is not evenly dispersed in the PLA matrix, resulting in a separate decomposition of the plasticizer from the PLA matrix decomposition. Zubir et al. [11] explained that the incompatible phase difference between plasticizer and PLA resulted in two decomposition peaks. When viewed from the ease of dispersion or the effect of plasticizers on the mobility of the PLA polymer chain arrangement, PEG-based plasticizers are easier to disperse than GTA plasticizers.

The parameters of the thermal stability of PLA biocomposite obtained from the TGA and DTG analysis can be seen in Table 2, with observations only at the second peak for PLAG. The measured parameters in Table 2 obtained from the TGA thermogram include $\mathrm{T}_{\text {onset, }}$ initial decomposition temperature $\left(\mathrm{T}_{\mathrm{o}}\right)$, decomposition peak temperature $\left(\mathrm{T}_{\max }\right)$, and final decomposition temperature $\left(\mathrm{T}_{\mathrm{t}}\right)$. Meanwhile, the DTG thermogram states the differential weight loss against temperature changes includes the temperature when the weight loss reaches 5\% ( $\mathrm{T}_{5}$ ), 50\% ( $\mathrm{T}_{50}$ ), and 95\% ( $\mathrm{T}_{95}$ ), and char residue at $450^{\circ} \mathrm{C}$. There was a decrease in $\mathrm{T}_{\text {onset, }}$ $\mathrm{T}_{\mathrm{o}}, \mathrm{T}_{\max }, \mathrm{T}_{\mathrm{t}}$ for all types of plasticizers. The reduction may be due to the plasticizer coating the surface and breaking down polymer interactions, particularly low molecular weight [12, 17]. PLAP200 has the most reduction compared to PLAG and PLAP4000. The observation on T5 shows that PLAG decomposes faster than PLAP, then increases again after $\mathrm{T}_{50}$ and $\mathrm{T} 95$. This indicates partial evaporation of GTA at the onset of heating [32].

In contrast, PLAP4000 provides better thermal resistance than PLAG and PLAP200 for all decomposition points ( $\left.\mathrm{T}_{5}, \mathrm{~T}_{50}, \mathrm{~T} 95\right)$ and char residue, which shows a higher value than PLA, PLAG, and PLAP200. In this sense, PLAP has a broader range of processing, application, and storage temperatures than PLAG so that it can be processed and stored at temperatures above $200^{\circ} \mathrm{C}$. The manufacturing process of PLA composites is in the temperature range of $170-180^{\circ} \mathrm{C}$. 


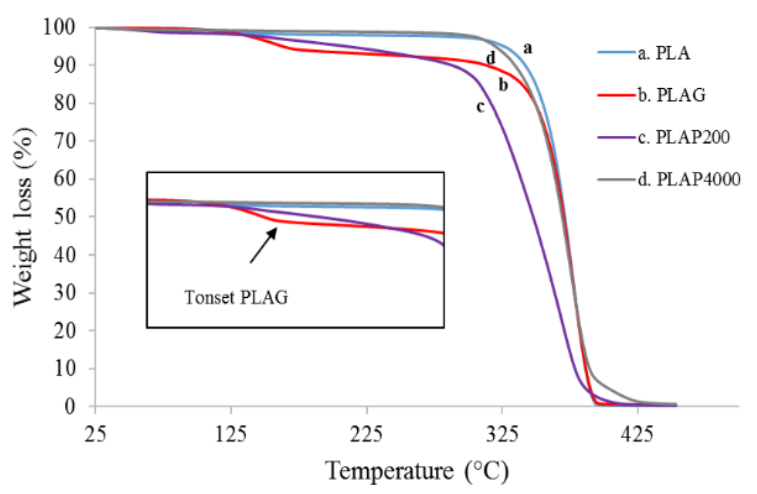

a.

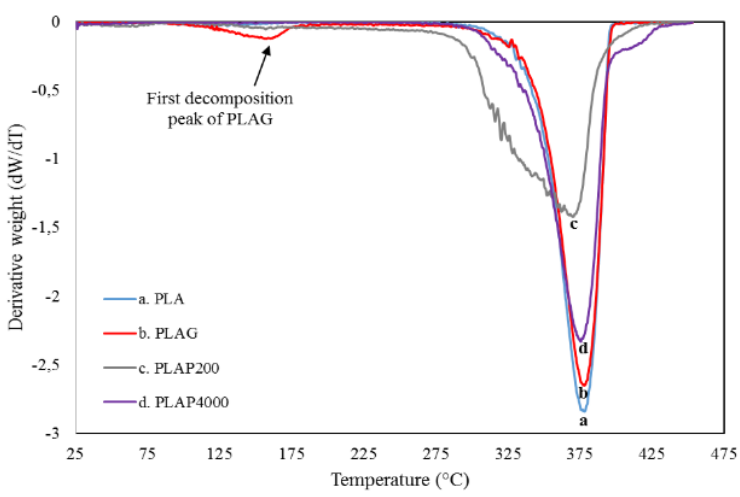

Figure 2. The PLA biocomposite thermogram with various types of plasticizers obtained through TGA (a) and DTG (b) analysis

The bleached OPF pulp in the form of microfibers is added to plasticized PLA composite with various types of plasticizers. The thermal stability characteristics of PLA composites with the addition of OPF and plasticizer obtained through TGA and DTG analysis are presented in Figures 3(a) and 3(b). The addition of OPF to PLA either with a plasticizer or not resulted in a decrease in $\mathrm{T}_{\text {onset. }}$. This is related to the thermal nature of lignocellulosic materials (hemicellulose and cellulose) which decompose in the range of $200-350^{\circ} \mathrm{C}[1,33,34]$. However, this decrease can also be attributed to the low dispersed OPF microfibers in PLA despite the presence of plasticizers. These results differ from studies conducted by Haafiz et al. [25] and Safdari et al. [35], which showed an increase in thermal stability after adding micro and nanofibers to the PLA due to good dispersion, thus suppressing the mobility of the PLA chain. The same trend also occurs in the plasticized PLA/OPF system, where PLAOP4000 gives a higher $\mathrm{T}_{\text {onset }}$ value than PLAOP200, while PLAOG produces two Tonsets, as shown in Figure 3(a) and Figure 3(b).

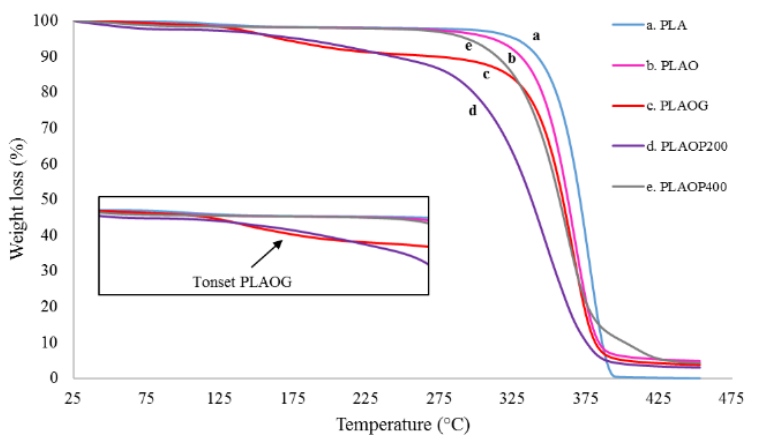

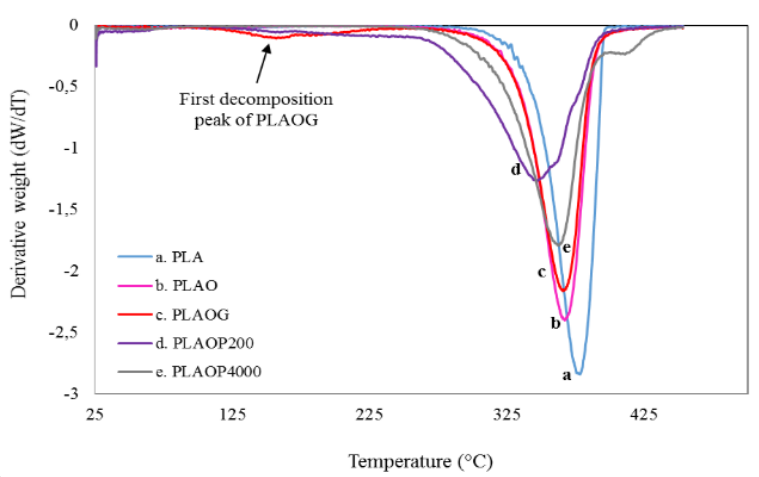

Figure 3. Biocomposite PLA thermogram with various types of plasticizers and OPF obtained through TGA (a) and DTG (b) analysis

The weight-loss parameters for temperature are presented in Table 2, where the Tonset for PLAOG is only shown at the second peak. The DTG data review shows that $\mathrm{T}_{\mathrm{o}}, \mathrm{T}_{\max }$, and $\mathrm{T}_{\mathrm{t}}$ with the addition of OPF have decreased in value compared to pure PLA and plasticized PLA. A similar trend occurred in plasticized PLA composites with the addition of $\mathrm{OPF}$ for $\mathrm{T}_{5}$ and $\mathrm{T}_{50}$, where PLAOG had the lowest $\mathrm{T}_{5}$ value then increased when it reached $\mathrm{T}_{50} 0$ compared to PLAOP. However, when it reached T95, PLAOP4000 increased instantaneously with the char residue obtained reaching $0.43 \%$. In this case, PEG4000 has the ability as a compatibilizer and plasticizer simultaneously [35]. Char residue of PLA composites with the addition of $\mathrm{OPF}$, has a higher value than pure PLA and plasticized PLA. This shows that the carbon atoms in PLA are converted to gas, while the OPF microfibers become carbon.

Table 2. Value of thermal stability parameters based on the weight loss obtained through TGA and DTG analysis

\begin{tabular}{|c|c|c|c|c|c|c|c|c|}
\hline \multirow[b]{2}{*}{ Code } & \multirow[b]{2}{*}{$\begin{array}{l}\mathrm{T}_{\text {onset }} \\
\left({ }^{\circ} \mathrm{C}\right)\end{array}$} & \multirow[b]{2}{*}{$\mathrm{T}_{\mathrm{o}}\left({ }^{\circ} \mathrm{C}\right)$} & \multirow[b]{2}{*}{$\begin{array}{l}\mathrm{T}_{\max } \\
\left({ }^{\circ} \mathrm{C}\right)\end{array}$} & \multirow[b]{2}{*}{$\mathrm{T}_{\mathrm{t}}\left({ }^{\circ} \mathrm{C}\right)$} & \multicolumn{3}{|c|}{ Weight loss } & \multirow{2}{*}{$\begin{array}{c}\text { Char residue } \\
\text { at } 450^{\circ} \mathrm{C} \\
(\%)\end{array}$} \\
\hline & & & & & $\begin{array}{l}\mathrm{T} 5 \\
\left({ }^{\circ} \mathrm{C}\right)\end{array}$ & $\begin{array}{l}\text { T50 } \\
\left({ }^{\circ} \mathrm{C}\right)\end{array}$ & $\begin{array}{l}\text { T95 } \\
\left({ }^{\circ} \mathrm{C}\right)\end{array}$ & \\
\hline PLA & 356.44 & 345.31 & 377.4 & 395.1 & 326.24 & 370.97 & 389.08 & 0.001 \\
\hline PLAG & 353.33 & 343.68 & 376.69 & 395.47 & 162.79 & 369.44 & 388.88 & 0.037 \\
\hline PLAP200 & 315.4 & $\begin{array}{c}296.0 \\
5\end{array}$ & 368 & 389.13 & 210.17 & 346.83 & 385.34 & 0.022 \\
\hline PLAP4000 & 349.17 & 336.65 & 374.68 & 395.78 & 319.99 & 369.01 & 402.14 & 0.063 \\
\hline PLAO & 343.18 & 331.63 & 366.25 & $\begin{array}{c}389.0 \\
9\end{array}$ & 310.54 & 362.17 & 440.05 & 0.483 \\
\hline PLAOG & 341.02 & 329.67 & 364.87 & 387.64 & 164.8 & 358.64 & 401.52 & 0.379 \\
\hline PLAOP200 & 309.43 & 291.44 & 346.39 & 385.35 & 176.87 & 337.41 & 389.13 & 0.300 \\
\hline $\begin{array}{c}\text { PLAOP400 } \\
0\end{array}$ & 330.14 & 318.22 & 361.17 & 386.7 & 293.44 & 356.74 & 429.79 & 0.431 \\
\hline
\end{tabular}

\subsection{Thermal characteristics of PLA biocomposites through DSC analysis}

DSC analysis provides information about the parameters of the thermal properties of PLA biocomposites, including $\mathrm{Tm}, \mathrm{T}_{\mathrm{c}}$, and $\mathrm{T}_{\mathrm{g}}$, along with their energy. One of the weaknesses of PLA is that the high $\mathrm{T}_{\mathrm{g}}$ value reaches $59.73^{\circ} \mathrm{C}$, as presented in Table 3 . The decrease in $\mathrm{Tg}_{\mathrm{g}}$ value occurred with the addition of a plasticizer even up to $42.84 \%$ in the PLAP200. The peak of $\mathrm{T}_{\mathrm{g}}$ widens, and there is a point shift for PLA with the addition of a plasticizer, as shown in Figure 4 (a). The decrease in $\mathrm{T}_{\mathrm{g}}$ is due to the broader mobility of the 
plasticizer chain, making PLA more flexible [12, 17, 18, 35]. Semicrystalline PLA is unique. At a certain point during the endothermic process, it undergoes selfnucleating before melting occurs, which is known as cold crystallization, as shown in Figure 4 (a). A similar event occurred in PLAG, although the point shift occurred due to the decrease in $\mathrm{T}_{\mathrm{g}}$.

However, with the PEG plasticizer, there was a reduction in the area on the PLAP4000, as indicated by a decrease in the $\Delta \mathrm{H}_{\mathrm{cc}}$ value in Table 3 . There was even no cold crystallization peak formation on the PLAP200. In this case, PEG can accelerate the crystal formation process in PLA. Cold crystallization formationindicate a slow crystallization process and amorphous PLA [23]. On the other hand, the sloping $\Delta \mathrm{H}_{\mathrm{cc}}$ shows higher PLA crystallization, and the absence of $\mathrm{T}_{\mathrm{cc}}$ indicates that PLA has crystallized in a certain order, which means that PEG functions as a crystal nucleating agent [20, 24]. The endothermic curve of pure PLA yielded two peaks, indicating that there was a melting of different crystal structures (regular and irregular) after cold crystallization (shown as arrows in Figure 4 (a).) This suggests that to obtain a regular crystal structure from irregular crystals requires a slower reorganization process $[20,22]$. As explained by Salas-Papayanopolos et al. [18], there is a reorganization of unstable $\alpha$ ' crystals into a more stable $\alpha$. The addition of a plasticizer gave different results, where only one peak was formed, which referred to the formation of one type of crystal. These results also indicate that there is no crystal phase separation [17]. The melting point (Tm) values decrease considerably, reaching $31.8 \%$; $42.8 \%$; and $27.3 \%$ for PLAG, PLAP200, and PLAP4000, respectively, compared to pure PLA. This reduction in $\mathrm{T}_{\mathrm{m}}$ contributes to the determination of the process production, application, distribution, and storage of PLA biocomposites in synergy with the decomposition temperature.

Figure 4 (b) shows that the PLAP200 and PLAP4000 produce exothermic curves with sharp peaks while PLA and PLAG are extensive. These results indicate that PLA and PLAG did not undergo a complete crystallization process. Therefore, PLA requires a nucleating agent to accelerate crystallization because PLA tends to undergo slow crystallization. The results presented in Figure 4 (b) and Table 3 show that PEG plasticizer can be a nucleating agent compared to GTA. The degree of crystallization (Xc) also increased for PLA with PEG plasticizers, both with low and high molecular weights. This may be because of the ease of insertion of molecules between the PLA polymer chains. Increasing chain mobility resulted in a decrease in $\mathrm{T}_{\mathrm{g}}$ and $\mathrm{T}_{\mathrm{cc}}$, which contributed to an increase in the crystallization rate [17].

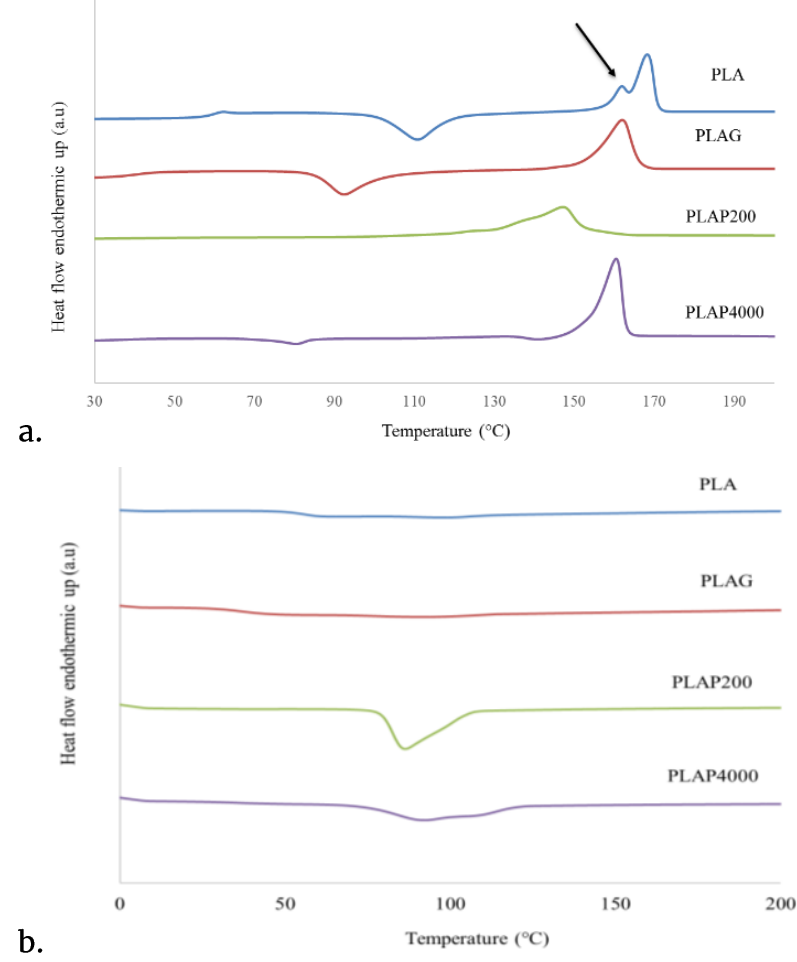

Figure 4. The DSC thermogram of PLA biocomposite with various types of plasticizers during endothermic (a) and exothermic (b) processes

Table 3. The value of the thermal parameters based on the DSC analysis

\begin{tabular}{|c|c|c|c|c|c|c|c|c|}
\hline Code & $\mathrm{T}_{\mathrm{g}}\left({ }^{\circ} \mathrm{C}\right)$ & $\mathrm{T}_{\mathrm{m}}\left({ }^{\circ} \mathrm{C}\right)$ & $\Delta \mathrm{H}_{\mathrm{m}}(\mathrm{W} / \mathrm{g})$ & $\mathrm{T}_{\mathrm{cc}}\left({ }^{\circ} \mathrm{C}\right)$ & $\Delta \mathrm{H}_{\mathrm{cc}}(\mathrm{W} / \mathrm{g})$ & $\mathrm{T}_{\mathrm{c}}\left({ }^{\circ} \mathrm{C}\right)$ & $\Delta \mathrm{H}_{\mathrm{c}}(\mathrm{W} / \mathrm{g})$ & $\mathrm{X}_{\mathrm{c}}(\%)$ \\
\hline PLA & 59.73 & 168.22 & 34.79 & 110.88 & -26.41 & 63.8 & -15.33 & 37.40 \\
\hline PLAG & 40.72 & 161.91 & 34.75 & 92.53 & -22.27 & 85.14 & -19.13 & 37.36 \\
\hline PLAP200 & 34.14 & 147.11 & 43.11 & - & - & 86.52 & -35.20 & 46.35 \\
\hline PLAP4000 & 43.45 & 166.52 & 44.20 & 86.67 & -3.25 & 92 & -25.50 & 47.53 \\
\hline PLAO & 60.61 & 168.06 & 30.91 & 111.18 & -20.43 & 97.82 & -15.18 & 36.93 \\
\hline PLAOG & 60.38 & 167.26 & 27.85 & 111.37 & -19.37 & 98.47 & -15.20 & 33.28 \\
\hline PLAOP200 & 26.56 & 149.95 & 29.62 & - & - & 95.66 & -27.55 & 35.39 \\
\hline PLAOP 4000 & 37.36 & 166.07 & 28.56 & - & - & 94.32 & -22.35 & 34.12 \\
\hline
\end{tabular}

The addition of OPF to the PLA matrix did not significantly affect the thermal properties of PLA biocomposites. Even there was an increase in $\mathrm{T}_{\mathrm{g}}$ in PLAO and PLAOG, as presented in Table 3. In contrast to the PLAOP200 and PLAOP4000 biocomposites, the Tg value decreased by $55.5 \%$ and $37.5 \%$. Meanwhile, similar characteristics to PLA occur in PLAO and PLAOG, where a cold crystallization occurs, and two peaks form on the endothermic curve (shown by arrows in Figure 5 (b)). Different results occurred in PLAOP200 and PLAOP4000 were no cold crystallization occurred, and one peak was formed on the endothermic curve. This is because OPF cannot accelerate the arrangement of the orderly crystal structure in PLAO and PLAOG. The addition of OPF to PLA and plasticized PLA caused a decrease in the degree of crystallization (Xc) compared to pure PLA. According to Safdari et al. [35], cellulose fibers to PLA can inhibit polymer chain mobility and crystal growth, thereby increasing stiffness, increasing in $\mathrm{T}_{\mathrm{g}}$ value and decrease in Xc, if it is not adequately dispersed.

Figure 5 (b) shows the exothermic curve of the effect of OPF addition on PLA and plasticized PLA. Both PLAO 
and PLAOG show broad peaks like PLA, but for the PLAOP200 and PLAOP4000, the exothermic curve peaks are narrower. In this case, $\mathrm{OPF}$ can still act as nucleating agent for PLA with PEG plasticizers. PEG still contributes to the dispersion ability of OPF in the PLA matrix. Apart from being a plasticizer, PEG also functions as a compatibilizer, so that it has a better effect on the formation of PLA crystals compared to GTA. The crystallization peaks during the exothermic process are getting sharper, suggesting that there is a surface interaction between cellulose and PLA [23], thereby increasing the nucleus-forming free area and encouraging crystallization [24].

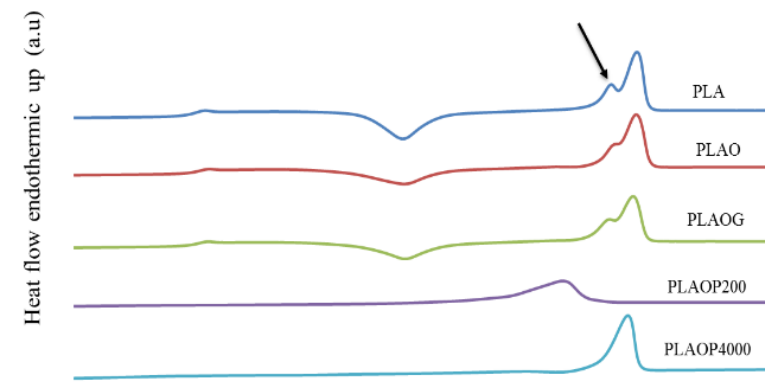

a.
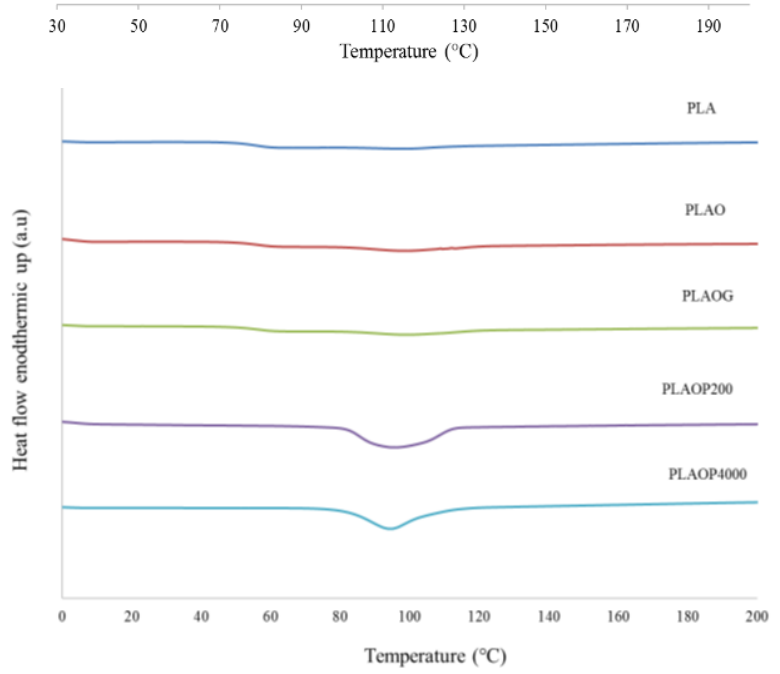

b.

Figure 5. Thermogram analysis of PLA biocomposite DSC with various types of plasticizers and OPF during endothermic (a) and exothermic (b) processes

\subsection{Overview of PLA Biocomposite Crystallization Kinetics}

The crystallization kinetics of PLA biocomposites was carried out through the Avrami model approach, which explains the crystallization mechanism or the total solidification of thermoplastic polymers. Total crystallization includes the process of nucleation and crystal growth [27, 28]. The discussion on kinetics is more focused on PLA biocomposite with PEG plasticizer and the addition of OPF. The DSC analysis results show a much different change, especially in the crystallization process (exothermic conditions), compared to GTA plasticized PLA. The DSC analysis results showed that the PEG plasticizer and OPF microfibers were effective as nucleating agents. However, the effect can only be explained by the analysis of crystallization kinetics.
Analysis of the crystallization kinetics using the Avrami model can determine the value of the constant $\mathrm{K}$, which shows the total crystallization rate and the value of $n$, which shows the formed crystals geometry.

The crystallization process of PLA biocomposite through the Avrami model was obtained by connecting the stratified logarithmic graph of relative crystallization. The logarithmic of the temperature function in the non-isothermal crystallization process. The results of the graph plots are presented in Figure 6 for each cooling rate. Figure 6 presents a linear line showing that the Avrami model fits a PLA biocomposite system at all cooling rates.

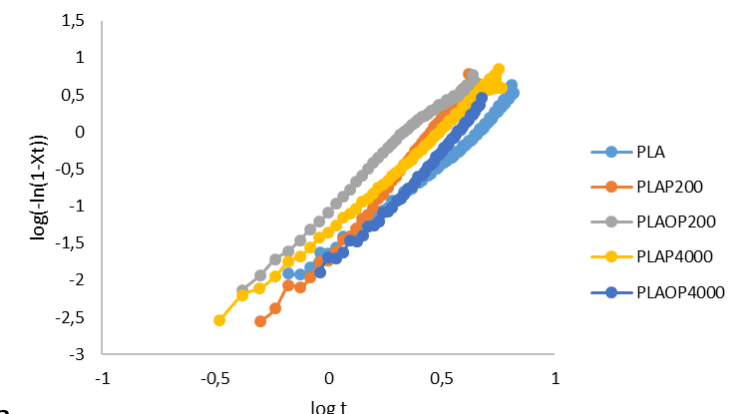

a.

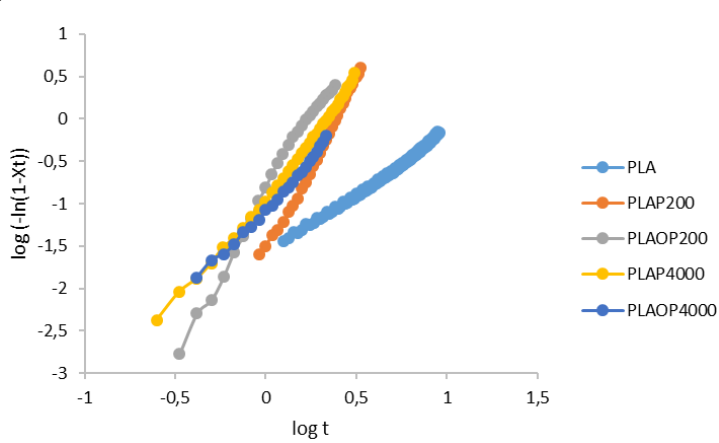

b.

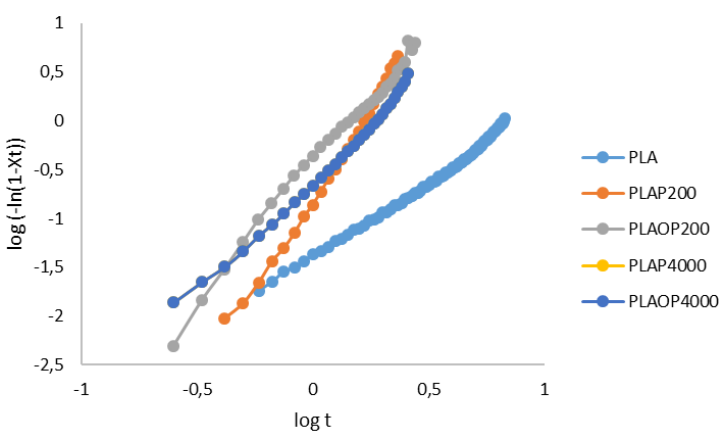

Figure 6. The relationship between $\log (-\ln (1-\mathrm{Xt}))$ and $\log t$ of the Avrami model of PLA biocomposite at cooling rates of $5^{\circ} \mathrm{C} /$ minute $(\mathrm{a}), 10^{\circ} \mathrm{C} /$ minute (b), and $15^{\circ} \mathrm{C} /$ minute.

The crystallization rate constant $(\mathrm{K})$ and crystal geometry are presented in Table 4. The $K$ values indicated an increase for PEG 200 and PEG 4000 plasticized PLA at all cooling rates. This shows that the PEG plasticizer is effective as a nucleating agent and a crystal. However, with the addition of OPF, the PLAOP4000 only gave 3.7 and 2.3 times increase in cooling rates of $10^{\circ} \mathrm{C} / \mathrm{min}$ and $15^{\circ} \mathrm{C} / \mathrm{min}$, respectively. In contrast to the PLAOP200, which still showed an increase of 4.2, 5.2, and 9.2 times for cooling rates of 5 , 
10 , and $15^{\circ} \mathrm{C} / \mathrm{min}$, respectively. Different results were reported by Ding et al. [36], in which the presence of cellulose in PLA composites gave an increase in $K$ value because cellulose was effective as a crystal nucleating agent.

The value of $n$ is an integer number between 1- 4, where the value of $n$ between 2-3 indicates the threedimensional crystal growth dimension, while the $n$ value $<1$ and $\mathrm{n}>3$ indicates 2-dimensional crystal [27, 28]. Besides showing the dimension of crystal growth, the value of $\mathrm{n}$ can describe the mechanism of crystal growth. The value of $\mathrm{n}<2$ describes the mechanism of crystal growth homogeneously and simultaneously. The values of $n=2-3$ are heterogeneous and simultaneous, while more $n>3$ are homogeneous and sporadic $[4,37,38,39]$. Table 4 shows the results of $n$ values between 2-3 on the PLAOP200, PLAP4000, and PLAOP4000. These results explain that the crystallization mechanism that occurs is heterogeneous crystallization and simultaneous crystallization with 3-dimensional crystals formed. Whereas in PLA, only with a speed of $5^{\circ} \mathrm{C} / \mathrm{min}$, which results in $n$ at a value of $2-3$. This shows that the crystallization of PLA is slow because, with a cooling rate of more than that, the value of $\mathrm{n}$ is $1-2$. Different results were also obtained for the PLAP200, which resulted in a value of $n>3$, which indicates that the crystals formed were denser. These results indicate that the crystallization process at a rate of $5-15^{\circ} \mathrm{C} / \mathrm{min}$ is too slow for the PLAP200. Thus, PEG plasticizers can be said to be very effective as nucleating agents and increase the crystallization rate of PLA, which is generally between 1$3^{\circ} \mathrm{C} / \mathrm{min}[8]$.

Table 4. Avrami Constants of PLA Biocomposites

\begin{tabular}{ccccc}
\hline Code & $\emptyset\left({ }^{\circ} \mathrm{C} / \mathrm{min}\right)$ & $\mathrm{K}$ & $\mathrm{n}$ & $\mathrm{R}^{2}$ \\
\hline PLA & 5 & 0.02208 & 2.5547 & 0.990 \\
& 10 & 0.02336 & 1.4785 & 0.992 \\
PLAP200 & 15 & 0.03831 & 1.6037 & 0.991 \\
& 5 & 0.02275 & 3.6256 & 0.994 \\
PLAOP200 & 10 & 0.02574 & 4.1188 & 0.994 \\
& 15 & 0.16025 & 3.6982 & 0.993 \\
PLAP4000 & 5 & 0.09389 & 2.7791 & 0.991 \\
& 10 & 0.12954 & 3.7247 & 0.990 \\
& 15 & 0.35197 & 2.7758 & 0.992 \\
PLAOP4000 & 5 & 0.05176 & 2.6357 & 0.995 \\
& 10 & 0.12639 & 2.6638 & 0.994 \\
& 15 & 0.24205 & 2.3143 & 0.991 \\
& 5 & 0.02178 & 2.8527 & 0.985 \\
& 10 & 0.08762 & 2.2913 & 0.992 \\
& 15 & 0.08904 & 2.6796 & 0.990 \\
\hline
\end{tabular}

\section{Conclusions}

The addition of plasticizers and microfibers from OPF affected the thermal resistance properties of PLA biocomposites. PLAP4000 has better thermal resistance compared to PLAP200 and PLAG with $\mathrm{T}_{\text {onset }}$ and $\mathrm{T}_{\max }$ values reaching $349.17^{\circ} \mathrm{C}$ and $374.68^{\circ} \mathrm{C}$, respectively, approaching pure PLA. The addition of OPF reduces the thermal stability of all plasticized PLA, both with GTA and PEG. The crystallinity analysis of the DSC analysis showed that PEG has the ability as a nucleating agent better than GTA with the formation of an endothermic peak, a decrease in $\mathrm{T}_{\mathrm{cc}}$, and an increase in $\mathrm{T}_{\mathrm{c}}$ in the exothermic process. All types of plasticizers reduced the $\mathrm{T}_{\mathrm{g}}$ value by about $27-42 \%$, while the addition of $\mathrm{OPF}$ reduced the $\mathrm{T}_{\mathrm{g}}$ in PLA with the PEG plasticizer ranging from $37-55 \%$. A review of crystallization kinetics shows that the crystallization rate increases with PEG and OPF plasticizers, which is around 4-9 times for PEG200, while 2-3 times for PEG4000. The crystal formation phenomenon occurs in 3-dimensional crystals with heterogeneous and simultaneous crystallization mechanisms where the value of $n$ ranges from $2-3$ at a cooling rate of $5-15^{\circ} \mathrm{C} /$ minute. PEG produces PLA composites that are better than GTA because it can function as a nucleating agent and a compatibilizer between OPF and PLA. Overall, PEG4000 has better thermal resistance properties, a nucleating agent, and better compatibility than PEG200 and GTA, but the presence of OPF inhibits crystallization in PLA composites.

\section{Acknowledgments}

The author would like to thank the 2019 Thematic DIPA program from the Research center for Biomaterials - LIPI, which has funded this research activity. The author also thanks Dr. Lisman Suryanegara as the mentor in this activity, so that this research can run well.

\section{References}

[1] M. S. Huda, L. T. Drzal, M. Misra, A. K. Mohanty, Wood-Fiber-Reinforced Poly(Lactic Acid) Composites: Evaluation of the Physicomechanical and Morphological Properties, Journal of Applied Polymer Science, 102, 5, (2006), 4856-4869 https://doi.org/10.1002/app.24829

[2] Rahul M. Rasal, Amol V. Janorkar, Douglas E. Hirt, Poly(Lactic Acid) Modifications, Progress in Polymer Science, 35, 3, (2010), 338-356 https://doi.org/10.1016/j.progpolymsci.2009.12.003

[3] Maria Laura Di Lorenzo, Crystallization Behavior of Poly(L-Lactic Acid), European Polymer Journal, 41, 3, (2005), 569-575

https://doi.org/10.1016/j.eurpolymj.2004.10.020

[4] Sajjad Saeidlou, Michel A. Huneault, Hongbo Li, Chul B. Park, Poly(Lactic Acid) Crystallization, Progress in Polymer Science, 37, 12, (2012), 1657-1677 https://doi.org/10.1016/j.progpolymsci.2012.07.005

[5] Rafael A. Auras, Bruce Harte, Susan Selke, Ruben Hernandez, Mechanical, Physical, and Barrier Properties of Poly(Lactide) Films, Journal of Plastic Film \& Sheeting, 19, 2, (2003), 123-135 https://doi.org/10.1177/8756087903039702

[6] 0. Martin, L. Avérous, Poly(Lactic Acid): Plasticization and Properties of Biodegradable Multiphase Systems, Polymer, 42, 14, (2001), 62096219 https://doi.org/10.1016/S0032-3861(01)00086-6

[7] B. Eling, S. Gogolewski, A. J. Pennings, Biodegradable Materials of Poly(L-Lactic Acid): 1 . Melt-Spun and Solution-Spun Fibres, Polymer, 23, 11, (1982), 1587-1593 https://doi.org/10.1016/0032-3861(82)90176-8

[8] R. Vasanthakumari, A. J. Pennings, Crystallization Kinetics of Poly(L-Lactic Acid), Polymer, 24, 2, 
(1983), 175-178

https://doi.org/10.1016/0032-3861(83)90129-5

[9] W. Hoogsteen, A. R. Postema, A. J. Pennings, Gerrit Ten Brinke, P. Zugenmaier, Crystal Structure, Conformation and Morphology of Solution-Spun Poly(L-Lactide) Fibers, Macromolecules, 23, 2, (1990), 634-642

https://doi.org/10.1021/ma00204a041

[10] L. T. Lim, R. Auras, M. Rubino, Processing Technologies for Poly(Lactic Acid), Progress in Polymer Science, 33, 8, (2008), 820-852 https://doi.org/10.1016/j.progpolymsci.2008.05.004

[11] Nurul Hani Md Zubir, Sung Ting Sam, Nik Noriman Zulkepli, Mohd Firdaus Omar, The Effect of Rice Straw Particulate Loading and Polyethylene Glycol as Plasticizer on the Properties of Polylactic Acid/Polyhydroxybutyrate-Valerate Blends, Polymer Bulletin, 75, 1, (2018), 61-76 https://doi.org/10.1007/s00289-017-2018-y

[12] Athanasia Amanda Septevani, Samsul Bhakri, Plasticization of Poly(Lactic Acid) Using Different Molecular Weight of Poly(Ethylene Glycol), AIP Conference Proceedings, 1904, 1, (2017), 020038 https://doi.org/10.1063/1.5011895

[13] Bettina Dittrich, Karen-Alessa Wartig, Daniel Hofmann, Rolf Mülhaupt, Bernhard Schartel, The Influence of Layered, Spherical, and Tubular Carbon Nanomaterials' Concentration on the Flame Retardancy of Polypropylene, Polymer Composites, 36, 7, (2015), 1230-1241 https://doi.org/10.1002/pc.23027

[14] Kyung-man Choi, Myeon-Cheon Choi, Dong-Hun Han, Tae-Sung Park, Chang-Sik Ha, Plasticization of Poly(Lactic Acid) (PLA) through Chemical Grafting of Poly(Ethylene Glycol) (PEG) Via in Situ Reactive Blending, European Polymer Journal, 49, 8, (2013), 2356-2364 https://doi.org/10.1016/j.eurpolymj.2013.05.027

[15] Isabelle Pillin, Nicolas Montrelay, Yves Grohens, Thermo-Mechanical Characterization of Plasticized PLA: Is the Miscibility the Only Significant Factor?, Polymer, 47, 13, (2006), 4676-4682

https://doi.org/10.1016/j.polymer.2006.04.013

[16]Justine Muller, Alberto Jiménez, Chelo GonzálezMartínez, Amparo Chiralt, Influence of Plasticizers on Thermal Properties and Crystallization Behaviour of Poly(Lactic Acid) Films Obtained by Compression Moulding, Polymer International, 65, 8, (2016), 970978 https://doi.org/10.1002/pi.5142

[17] Buong Woei Chieng, Nor Azowa Ibrahim, Wan Md Zin Wan Yunus, Mohd Zobir Hussein, Plasticized Poly(Lactic Acid) with Low Molecular Weight Poly(Ethylene Glycol): Mechanical, Thermal, and Morphology Properties, Journal of Applied Polymer Science, 130, 6, (2013), 4576-4580 https://doi.org/10.1002/app.39742

[18] Homero Salas-Papayanopolos, Ana B. MoralesCepeda, Saúl Sanchez, Pierre G. Lafleur, I. Gomez, Synergistic Effect of Silver Nanoparticle Content on the Optical and Thermo-Mechanical Properties of Poly(L-Lactic Acid)/Glycerol Triacetate Blends, Polymer Bulletin, 74, 12, (2017), 4799-4814 https://doi.org/10.1007/s00289-017-1992-4

[19]Xin-Feng Wei, Rui-Ying Bao, Zhi-Qiang Cao, LiangQing Zhang, Zheng-Ying Liu, Wei Yang, Bang-Hu
Xie, Ming-Bo Yang, Greatly Accelerated Crystallization of Poly(Lactic Acid): Cooperative Effect of Stereocomplex Crystallites and Polyethylene Glycol, Colloid and Polymer Science, 292, 1, (2014), 163-172

https://doi.org/10.1007/s00396-013-3067-X

[20]Xuetao Shi, Guangcheng Zhang, Thanh V. Phuong, Andrea Lazzeri, Synergistic Effects of Nucleating Agents and Plasticizers on the Crystallization Behavior of Poly(Lactic Acid), Molecules, 20, 1, (2015), 1579-1593

https://doi.org/10.3390/molecules20011579

[21] Ali Abdulkhani, Jaber Hosseinzadeh, Saeed Dadashi, Mohammad Mousavi, A Study of Morphological, Thermal, Mechanical and Barrier Properties of PLA Based Biocomposites Prepared with Micro and Nano Sized Cellulosic Fibers, Cellulose Chemistry and Technology, 49, 7-8, (2015), 597-605

[22]Yong-Qing Zhao, Hoi-Yan Cheung, Kin-Tak Lau, Cai-Ling Xu, Dan-Dan Zhao, Hu-Lin Li, Silkworm Silk/Poly(Lactic Acid) Biocomposites: Dynamic Mechanical, Thermal and Biodegradable Properties, Polymer Degradation and Stability, 95, 10, (2010), 1978-1987

https://doi.org/10.1016/j.polymdegradstab.2010.07.015

[23]Nicolas Le Moigne, Marc Longerey, Jean-Marie Taulemesse, Jean-Charles Bénézet, Anne Bergeret, Study of the Interface in Natural Fibres Reinforced Poly(Lactic Acid) Biocomposites Modified by Optimized Organosilane Treatments, Industrial Crops and Products, 52, (2014), 481-494 https://doi.org/10.1016/j.indcrop.2013.11.022

[24]Lisman Suryanegara, Antonio Norio Nakagaito, Hiroyuki Yano, Thermo-Mechanical Properties of Microfibrillated Cellulose-Reinforced Partially Crystallized PLA Composites, Cellulose, 17, 4, (2010), 771-778 https://doi.org/10.1007/s10570-010-9419-5

[25]M. K. Mohamad Haafiz, Azman Hassan, Zainoha Zakaria, I. M. Inuwa, M. S. Islam, M. Jawaid, Properties of Polylactic Acid Composites Reinforced with Oil Palm Biomass Microcrystalline Cellulose, Carbohydrate Polymers, 98, 1, (2013), 139-145 https://doi.org/10.1016/j.carbpol.2013.05.069

[26]E. W. Fischer, Hans J. Sterzel, G. Wegner, Investigation of the Structure of Solution Grown Crystals of Lactide Copolymers by Means of Chemical Reactions, Kolloid-Zeitschrift und Zeitschrift für Polymere, 251, 11, (1973), 980-990 https://doi.org/10.1007/BF01498927

[27]Melvin Avrami, Kinetics of Phase Change. II Transformation-Time Relations for Random Distribution of Nuclei, The Journal of Chemical Physics, 8, 2, (1940), 212-224 https://doi.org/10.1063/1.1750631

[28]Melvin Avrami, Kinetics of Phase Change. I General Theory, The Journal of Chemical Physics, 7, 12, (1939), 1103-1112 https://doi.org/10.1063/1.1750380

[29]Mehmet Kodal, Humeyra Sirin, Guralp Ozkoc, NonIsothermal Crystallization Kinetics of PEG Plasticized PLA/G-POSS Nanocomposites, Polymer Composites, 38, 7, (2017), 1378-1389 https://doi.org/10.1002/pc.23704

[30]T. Zimmermann, E. Pöhler, T. Geiger, Cellulose Fibrils for Polymer Reinforcement, Advanced 
Engineering Materials, 6, 9, (2004), 754-761 https://doi.org/10.1002/adem.200400097

[31] V. S. Giita Silverajah, Nor Azowa Ibrahim, Norhazlin Zainuddin, Wan Md Zin Wan Yunus, Hazimah Abu Hassan, Mechanical, Thermal and Morphological Properties of Poly(lactic acid)/Epoxidized Palm Olein Blend, Molecules, 17, 10, (2012), 11729-11747 https://doi.org/10.3390/molecules171011729

[32]L. Quiles-Carrillo, S. Duart, N. Montanes, S. TorresGiner, R. Balart, Enhancement of the Mechanical and Thermal Properties of Injection-Molded Polylactide Parts by the Addition of Acrylated Epoxidized Soybean Oil, Materials \& Design, 140, (2018), 54-63

https://doi.org/10.1016/j.matdes.2017.11.031

[33]Paola Giudicianni, Giuseppe Cardone, Raffaele Ragucci, Cellulose, Hemicellulose and Lignin Slow Steam Pyrolysis: Thermal Decomposition of Biomass Components Mixtures, Journal of Analytical and Applied Pyrolysis, 100, (2013), 213-222 https://doi.org/10.1016/j.jaap.2012.12.026

[34]Sarifah Fauziah Syed Draman, Rusli Daik, Famiza Abdul Latif, Said M. El-Sheikh, Characterization and Thermal Decomposition Kinetics of Kapok (Ceiba pentandra L.)-Based Cellulose, BioResources, 9, 1, (2014), 8-23

[35]Fatemeh Safdari, Pierre J. Carreau, Marie C. Heuzey, Musa R. Kamal, Effects of Poly(Ethylene Glycol) on the Morphology and Properties of Biocomposites Based on Polylactide and Cellulose Nanofibers, Cellulose, 24, 7, (2017), 2877-2893 https://doi.org/10.1007/s10570-017-1327-5

[36]WeiDan Ding, Raymond K. M. Chu, Lun Howe Mark, Chul B. Park, Mohini Sain, Non-Isothermal Crystallization Behaviors of Poly(Lactic Acid)/Cellulose Nanofiber Composites in the Presence of $\mathrm{CO}_{2}$, European Polymer Journal, 71, (2015), 231-247

https://doi.org/10.1016/j.eurpolymj.2015.07.054

[37]S. Iannace, L. Nicolais, Isothermal Crystallization and Chain Mobility of Poly(L-Lactide), Journal of Applied Polymer Science, 64, 5, (1997), 911-919 https://doi.org/10.1002/(SICI)10974628(19970502)64:5<911::AID-APP11>3.0.CO;2-W

[38]Yong He, Zhongyong Fan, Yanfei Hu, Tong Wu, Jia Wei, Suming Li, DSC Analysis of Isothermal MeltCrystallization, Glass Transition and Melting Behavior of Poly(L-Lactide) with Different Molecular Weights, European Polymer Journal, 43, 10, (2007), 4431-4439 https://doi.org/10.1016/j.eurpolymj.2007.07.007

[39]Yonghui Li, Caihong Chen, Jun Li, Xiuzhi Susan Sun, Isothermal Crystallization and Melting Behaviors of Bionanocomposites from Poly(Lactic Acid) and $\mathrm{TiO}_{2}$ Nanowires, Journal of Applied Polymer Science, 124, 4, (2012), 2968-2977 https://doi.org/10.1002/app.35326 